\title{
Research on the Transport Management System Zhengzhou Airport Economy Zone
}

\author{
Linghong WEI \\ China Urban Sustainable Transport Research Center (CUSTReC) \\ China Academy of Transportation Sciences \\ Beijing, China \\ e-mail: weilinghong@163.com
}

\begin{abstract}
Transport as the forerunner of social economy and basic industry, Scientific and efficient management system to build modern comprehensive transport system and achieve the important guarantee for sustainable economic and social development. Zhengzhou Airport Economy Zone is the first airport economy as the main experimental Zone, Transport management system is still in its initial stages, this paper through the analysis and evaluation of the present situation of the management system of the transport management system of Zhengzhou Airport Economy Zone, refines the development characteristics and problems of the transport management system, and analysis of transport trends and socio-economic development on the mechanism of transport management system requirements, finally puts forward the suitable for Zhengzhou Airport Economy Zone transportation management organization and organization management frame.
\end{abstract}

Keywords-transport; institutional reform; airport economy zone; research

\section{INTRODUCTION}

Zhengzhou Airport Economy Zone (Hereinafter "Zone”) is located in the southeast of Zhengzhou City, about 20 kilometers from the center city. As the first national strategy of economic development airports, Zone Beijing will build a comprehensive transportation hub for the characteristics of the National Center City and modern aviation metropolis, To achieve this goal, Zone will further improve the experimental area airports traffic management system, establish and improve to adapt to economic and social development, to meet the urban and rural residents convenient, efficient, economic security, traffic demand of traffic management system, build a modern comprehensive transportation system, improve the comprehensive transportation industry management capabilities, to achieve efficient and coordinated development of various modes of transport, to enhance the capacity and level of service of economic and social development, and for national economic and social development to provide quality service.

\section{DEVELOPMENT STATUS}

Since the establishment of Zone, as the foundation and guide of the social economic development, the transportation developed quickly, At present, Zone transport management system take the majority of cities in china is similar to the management system-the way, the branch of the management model, Zone has a total of 15 departments, including the transport functions of the transport committee, planning and Land Resources Bureau, the Municipal Environmental Protection Bureau, the comprehensive law enforcement bureau (as shown in figure). At the present, Zone's transport management system meet the needs of airport area economic development, but there are still many problems, such as management of distribution is not rational functions, enforcement responsibilities have crossed functioning difficulties; Urban passenger transport management responsibility has not yet been classified as a traffic authority; related issues such as the lack of policies, regulations, standards, Leading to the comprehensive advantages of large transport is difficult to play. To resolve problems in transport management in Zone, it is necessary to improve the existing management system, the progressive introduction of resource integration, integration of the integrated transport management system, to guarantee maximum to meet the market needs.

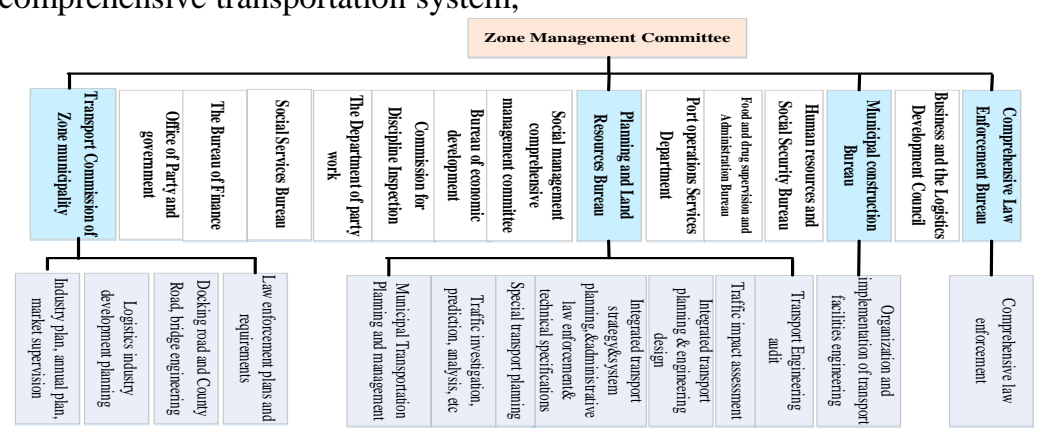

Figure 1. Division of functions of transportation in Zone 


\section{EXPERIENCE}

Shenzhen, a city that has been exploring the traffic management system reform in China, has experienced 8 landmark reforms, and the most recent one was in 2009.The special traffic planning, traffic signs and markings of the setting, signal lamp monitoring facilities, urban road management and raising of law enforcement functions assigned to the Transport Commission, Shenzhen has founded the " one city one transportation authority" mode of transportation administrative institution with international standards firstly in our country.2014,Shanghai, Tianjin and other cities have completed a new round of transportation management system reform, including the formation of Shanghai municipal commission of transport. Shanghai, The traffic planning, urban road, highway management, and coordination of comprehensive transportation, rail transportation planning, traffic signs, markings and other functions assigned to the Transport Commission. In addition, Shanghai promoted the improvement of transportation comprehensive coordination mechanism, established in provinces, municipalities directly under the central government level, the joint meeting of the Yangtze River Delta regional cooperation and development, at the municipal level set up security, energy saving and emission reduction, bus priority joint meeting of the coordination. Sum up, from the point of view of the comprehensive transportation management system and the development practice, the comprehensive transportation present integration trend of development, to build a comprehensive transportation management system and mechanism, has become an important guarantee for the sound and fast economic and social development. Developed cities of transportation are implemented centralized and unified, clear function, clear responsibilities of management system, namely comprehensive transportation management system of, reach the unified planning and coordinated development, downsizing, cost saving, convenient transportation, clean environment, reducing the cross link, can effectively promote the comprehensive development of transportation and social economy.

From the domestic integrated transport management system and development practice, there are four points of experience can be used for reference: Experience one: implementation of integrated management system." one city one transportation authority " development trend, the large department system turn interdepartmental coordination to coordination within the Department. Experience two: management style is clear and clearly defined powers and responsibilities. Widely used in integrated transportation management "decision making, implementation, monitoring," three-tier management mode of transportation. Experience three: strengthening the role of transportation planning in the management of integrated transport. Experience four: a high degree of rule of law in comprehensive transportation management.

\section{SITUATION ANALYSIS}

\section{A. Development Needs of Comprehensive Transport Management System in Zone}

- The rapid development of economy needs the support of the mechanism of comprehensive transport management system. To achieve the harmonious development of traffic and economy, first of all, it needs to break the system barriers and vigorously develop the large transport system.

- Rapid urbanization needs to be assisted by comprehensive transport management system. Urban agglomeration is the main trend of the urbanization development, it need to establish coordination mechanism between urban agglomeration; the reform of comprehensive transportation management system lays a good foundation for the integration of passenger transport on urban and rural

- The comprehensive transport system needs the support of necessary coordination mechanism. The diversification of traffic demand needs the support of the integrated system, and the integration of transportation needs the support of the integrated system and the coordination mechanism.

\section{B. Basic Judgment on the New Trend of Comprehensive Transport Management}

- Pay more attention to the innovation of management mechanism and means. Contradiction between supply and demand of roads, constraints of resources and environmental factors and the changes of the macro system, all these factors ask comprehensive transport management further innovate mechanism, improve efficiency, and make comprehensive use of legal, economic, administrative and other means, and to strengthen the connection with international common rules.

- Pay more attention to the systematic construction of cross-departmental interaction. With the increasing of the frequency large passenger flow and the phenomenon of traffic jams, and the further development of internal and external traffic, which means the existing multi sectoral linkage management mechanism should turn to the normalization, and institutionalization of the link mechanism.

\section{COUNTERMEASURE}

\section{A. Key Task}

During the 13th five-year plan, in the aspect of the concrete steps to promote the development of the comprehensive transport management system in Zone, suggests executing a progressive plan according to the actual situation. The first step is to innovate the coordination mechanism. By establishing and clarifying the special coordination mechanism of comprehensive transport management in Zone to special coordinate all types of issues 
in comprehensive transportation development planning, construction, management and so on, and to reduce the various friction caused by departmental segmentation. As an excessive way of system adjustment, the function of comprehensive coordination can be entrusted to the traffic of Zone, such as the double-level reviewing mechanism of transport and planning departments in Shenzhen. Based on the first step, the second step is to integrate the government management functions of road, railway, civil aviation, pipeline, urban public transport and other transport modes, to unified manage urban transportation and foreign transportation infrastructure, and the comprehensive transport management function will be entrusted to the Commission of Transport of Zone, which will realize the management system of "one city one transportation authority". Where condition permits, the third steps is to adjust and merge functions about transport planning, integrated development of land for traffic facilities, etc of Zone Planning and Land Resources Bureau, which can help to form institutions and systems that are more satisfactory with the requirements of integrated management and development and an multi-department management model of comprehensive transport .

Recent organizational structure includes decisionmaking layer, execution layer, and supervision layer. Decision layer is composed of commission eight institutions constitute, and executive layer is composed of six executive agency commissions, supervision layer composed of a nonpermanent supervision institutions. In addition, Commission of Transport also has the function of traffic combat readiness.

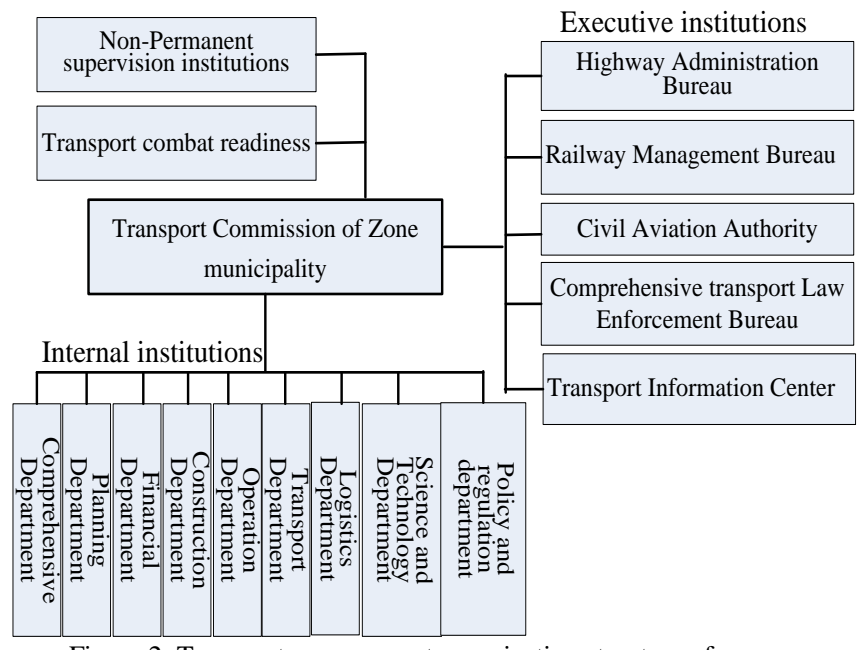

Figure 2. Transport management organization structure of zone

\section{B. Forward Key Task}

Consider the floor space, population size, speed of economic development and long-term development, if longterm Zone has the possibility of setting subordinate popedom, it will be necessary to further consider the comprehensive transport management system development of subordinate popedom. The comprehensive transport management system development of subordinate popedom is similar to that of Zone. Although the subordinate popedom is small, the scope of comprehensive transport management roughly the same, while its emphasis on comprehensive transport management is different with Zone. Taking into account the development trend of the forward part of the region, urban passenger transport and service-type government functions will become the focus of comprehensive transport management considerations of subordinate popedom.

Form a service oriented pattern: to further adjust and optimize the various modes of transport management functions, and service oriented transport management pattern has been basically formed.

Adapt to the development of the new demand: give full consideration to the long-term development of Zone, if it sets a subordinate popedom, it should also establish Transportation management department in the subordinate popedom.

Consider setting some subordinate popedom in forward, the subordinate popedom includes six internal organs, and Institutions will be set according to the need.

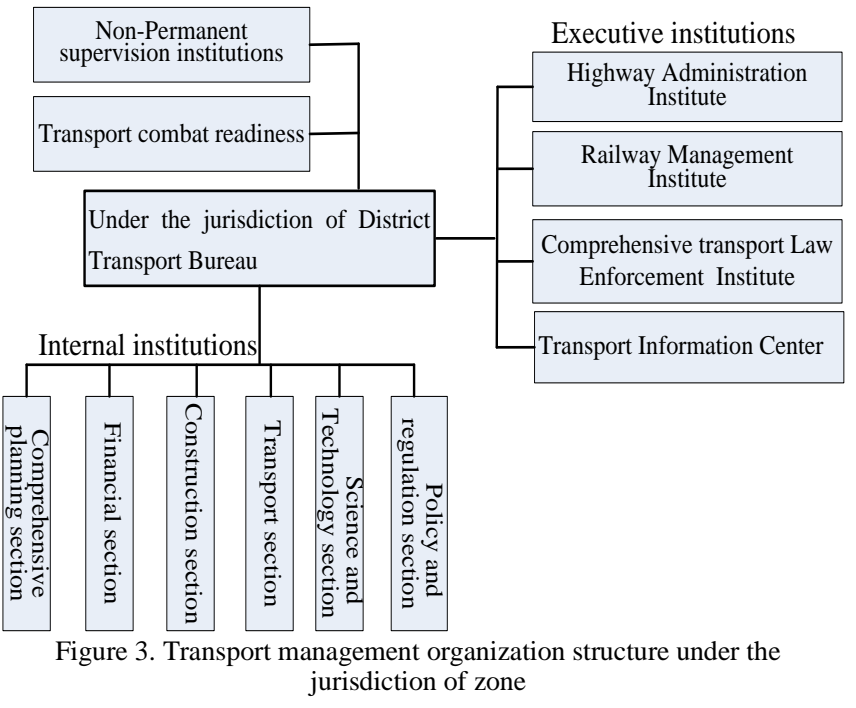

\section{CONCLUSIONS}

Based of Systematic analysis of current situation of transport management system of Zhengzhou Airport Economy Zone, this paper analysis the problems existing in the development, and draw excellent experiences of transport management system reform form Shenzhen, Shanghai, Tianjin and other domestic cities, and it also study and put forward development mode and frame structure of transport management system of Zone. The study provide theoretical basis and technical support for the development of transport management system of Zone, further to provide policy and technical support for development of transport management system of new ones of others in our country, which will effectively promote and improve the reform and development of China's transport management system, and enhance the ability of industry management. 


\section{ACKNOWLEDGMENT}

The research was financially supported by the Projects of "Research on the framework of urban agglomeration transportation development technology policy" (20164811).

\section{REFERENCES}

[1] Gao Jun. Innovation of Transportation Administrative Institution of Central City Based on Holistic Governance---A Case Study of Transportation Administrative Institutional Reform in Shenzhen [D]. WuHan: WuHan University, 2011.

[2] MAO Yao. Primary Exploration on Macro-Transportation Management System of Chongqing City [J]. Vol.12 no.5 journal of ChongQing jiaotong university (Social Sciences Edition) Oct.2012.

[3] Christopher Pollitt. Joined-Up Government: a Survey [J]. Political Studies Review, 2003, (1).

[4] Xue LuLu; Zhang Haitao. Shaping up sustainable urban transport authorities in China:status quo assessment and reforming solutions [Z]. BeiJing, 2014.
[5] Rong Chao. Research on comprehensive transportation system in China [J]. 2009.

[6] Ma Siqi. Research on Management System and Efficiency Evaluation based on Transportation Projects [D]. TianJin: Hebei University of Technology, 2011.

[7] JiaWenrui. Study on the influence of traffic management system on road transportation and national economy [D]. Jilin University, 2011.

[8] Tom Ling. Deliverling joined-up government in the UK: dimensions, issues andproblem [J]. Public Administration, Vo.1 80 No. 4, 2002 (627).

[9] ZhangWenyan. Analysis of urban traffic management system reform [J]. Transportation Enterprise Management, 2011, (7):27-29.

[10] Wang Ziming. Thoughts on the Countermeasures of establishing integrated transportation management system in China [J]. comprehensive transportation, 2007, ( 1):59-61.

[11] Xu Zuyuan. Deepen the reform of the administrative system of traffic management, and promote the transformation of government administrative functions [J]. China Water Transport, 2009, (1):7-10. 